\title{
RELIABILITY ANALYSIS OF BENDING, SHEAR AND DEFLECTION CRITERIA OF REINFORCED CONCRETE SLABS
}

\author{
O. S. Abejide* \\ DEPARTMENT OF Civil ENGINEERING, AHMADU BELLO UNIVERSITY, ZARIA, NIGERIA. \\ E-mail address: abejideos@yahoo.com
}

\begin{abstract}
Reliability analysis of the safety levels of the criteria for bending, shear and deflection of singly reinforced, concrete slabs, have been evaluated over the practical range of thicknesses $100 \mathrm{~mm}$ to $250 \mathrm{~mm}$. The First Order Reliability Method was employed in the evaluation procedure for continuous slabs of equal spans as a case study. Results indicate that the safety margins proposed and associated with the probability of failure (given as $1 \times 10^{-6}$ ) for singly reinforced concrete slabs, in the British [CP110; BS8110] and European [EC2] codes for design are not achieved at all. Also, the reliability levels are not uniform. Thus, the current design formulations are not as safe and reliable as predicted. This is because the intrinsic probability of failure, in bending, for example, is only 0.022, which, corresponds to an implied safety level of 2.015. Therefore, the design formulations in these codes need a review so that they can at least meet the target for approved structural safety as prescribed by the Joint Committee on Structural Safety.
\end{abstract}

Keywords: reinforced concrete slabs, bending, shear, deflection, reliability, design codes.

\section{INTRODUCTION}

In practice, a structural element such as a reinforced concrete slab is always subjected to stochastic loading in service. Therefore, it is imperative that the performance of any structural system be evaluated in a reliability-based environment. In this case, an appropriate method of solution must be sought that will define the constraints in a probabilistic setting. The method used in this work is the First Order Reliability Method (FORM) which may be referred to as a second order method [1].
The probability distributions of the design variables have been prescribed despite limited information. However, it is important also to recognize that regardless of the distribution of the individual variate, it is the distribution of the safety margin, $(R-S)$, that is important in the calculation of the probability of failure, $\mathrm{P}_{\mathrm{f}}$ [2]. It was also noted [2] that if the risk level is high (e.g $\mathrm{P}_{\mathrm{f}}>10^{-3}$ or $\beta<3.1$ ), the calculated probability of failure is not much different regardless of the type of distribution. But for a very small risk (e.g, $P_{f} \leq 10^{-3}$ or $\beta \geq 4.2$ ), the probability of failure could be sensitive to this distribution.

Table 1: Essential Design Parameters Used

\begin{tabular}{|c|c|c|c|c|}
\hline S/No & Basic Variables & Type & Mean & Coefficient Of Variation \\
\hline 1 & Compressive strength of concrete, $\mathrm{f}_{\mathrm{cu}}$ & Lognormal & $30 \mathrm{~mm}^{2}$ & 0.15 \\
\hline 2 & Characteristic strength of steel, $\mathrm{f}_{\mathrm{y}}$ & Lognormal & $460 \mathrm{~N} / \mathrm{mm}^{2}$ & 0.15 \\
\hline 3 & Breadth, b & Normal & $1000 \mathrm{~mm}$ & 0.045 \\
\hline 4 & Effective depth, d & Normal & $50-250 \mathrm{~mm}$ & 0.086 \\
\hline 5 & Live load, $\mathrm{Q}$ & Gumbel & 0.0015 & 0.37 \\
\hline 6 & Length, L & Normal & $3000-6000 \mathrm{~mm}$ & 0.044 \\
\hline 7 & Characteristic strength of links, $\mathrm{f}_{\mathrm{yv}}$ & Lognormal & $250 \mathrm{~N} / \mathrm{mm}^{2}$ & 0.15 \\
\hline 8 & Cross-sectional area of links, $A_{\mathrm{sv}}$ & Normal & $157.1 \mathrm{~N} / \mathrm{mm}^{2}$ & 0.036 \\
\hline 9 & Spacing of links, $S_{v}$ & Normal & $250 \mathrm{~N} / \mathrm{mm}^{2}$ & 0.009 \\
\hline 10 & Ratio $v_{c} / v_{s}$ & Normal & 0.6 & 0.3 \\
\hline
\end{tabular}

${ }^{*}$ Corresponding author, Tel: +234-803-590-8260 
In the second moment reliability method, the parameters of interest are first and second moments (means and variances), for the computation of safety indices [3]. It is also important to note that it is the Coefficient of Variation, COV (ratio of standard deviation to mean value) that are mostly published in literature [4,5]. Values of relevant parameters for the basic variables with their corresponding distributions, means and COV used herein are shown in Table 1. A computer program, FORM5, incorporating all the variables, and which has also been based on the First Order Reliability Method, was employed in the reliability analysis.

A study [6] has shown that all geometric variables, such as, the breadth, depth and spans of the slabs are normally distributed, while the concrete strength and strength of steel are log-normally distributed. All variables were normalized in the application of FORM5 in this presentation.

It is absolutely necessary to evaluate the resistance of a reinforced concrete slab in a probabilistic environment, since its component materials are varied individually and must be dependent on each other in order to achieve a slab structure that will resist loads as one unit.

Thus, models for the performance functions for the limit states need to be developed. The failure modes considered are the bending, shear and deflection. Therefore, for each safety margin as obtained from equating the resistance of the slab as proposed by the codes $[15,16,17]$ and the load effect calculated by simple structural analysis, the basic variables are identified while suggesting their statistical behaviour from literature. In order to achieve maximum values for moments and shear forces, two load combinations as recommended in the codes $[15,16]$ are studied as in Figure 1 for continuous slabs. The load predictions of the current European code [17] are numerically smaller than this value; thus the choice of the earlier loads combinations in the codes. From Figure 2, we may allow the following representations: $\mathrm{N}_{1}=Q_{\mathrm{k}}$ $(1.4 \alpha+1.6), \mathrm{N}_{2}=1.0 \alpha \mathrm{Q}_{\mathrm{k}}, \alpha=\mathrm{G}_{\mathrm{k}} / \mathrm{Q}_{\mathrm{k}}=$ load ratio; $\mathrm{Q}_{\mathrm{k}}$ $=$ live load on slab; and $\mathrm{G}_{\mathrm{k}}=$ dead load on slab.

\section{BASIS FOR RELIABILITY ANALYSIS AND TRANSFORMATIONS}

We note here that the general reliability index is defined with the assumption that the sole available information about the input variables, $\mathbf{x}$, is that they are uncertain, with their uncertainty quantified in terms of a second-moment representation. Also, one of the fundamental assumptions behind the definition of reliability index is informal rotation symmetry in the normalized space. But it is obvious that symmetry-disturbing restrictions are satisfied out of logical necessity or for physical reasons and mostly as prescribed by the distribution characteristics of the individual variables in a reliability-based domain.

Thus, the existence of a boundary of definition domain generally prevents the informational rotation symmetry with respect to the origin. If the definition domain is regular, it is however, in principle possible to represent the mechanical model and the considered n-dimensional limit state problem by the aid of a new set of variables $\mathbf{y}$, that without restrictions can take values everywhere in the new or transformed domain. The First-Order Reliability Method (FORM) proposed by researchers $[7,8,9]$ incorporates the Taylor series expansion of the performance function $\mathrm{g}(\mathrm{)}$ which, is linearized at some points, say, points $\left(\mathrm{Y}^{*}{ }_{1}, \mathrm{Y}^{*}{ }_{2}, \ldots\right.$ $\mathrm{Y}^{*}{ }_{\mathrm{M}}$ ), on the failure surface rather than at the mean. The linearizing point is called the design or the checking point. Basically, the procedure is as follows: With the limit state and its variables given by;

$$
Z_{M}=g\left(y_{1}, y_{2}, \cdots \cdots, y_{m}\right)
$$

the random variables, $Y_{i}$, are first transformed to reduced uncorrelated (for independent random variables $\mathrm{Y}_{\mathrm{i}}$ ) variables with zero mean and unit variance. That is,

$U_{i}=\frac{Y_{i}-\mu_{Y_{i}}}{\sigma_{Y_{i}}}$

where, $\mathbf{U}_{\mathrm{i}}={ }^{* *}, \mu_{\mathrm{Yi}}=$ mean and $\sigma_{\mathrm{Yi}}=$ standard deviation.

Now, for any variable having non-normal distribution, it can be transformed into normal standardized variable in accordance with the equality of probabilities. Thus, $Y_{\mathrm{i}}$ and $\mathrm{U}_{\mathrm{i}}$ can be related using,

$$
F\left(Y_{i}\right)=\Phi\left(U_{i}\right)
$$

so that

$$
U_{i}=\Phi^{-1}\left[F\left(Y_{i}\right)\right]
$$

By a Taylor power series expansion of Equation (3) in correspondence with the checking point vector $\underline{Y}^{*}$ and considering linear terms only,

$U_{i} \approx \Phi^{-1}\left[F\left(Y_{i}\right)\right]+\left[\delta \Phi^{-1} \frac{\left[F\left(Y_{i}\right)\right]}{\partial Y_{i}}\right]_{Y^{*}}\left(Y_{i}-Y_{i}^{*}\right)$

where, the notation:

$$
\left[\frac{\partial}{\partial Y_{i}} \Phi^{-1}\right]_{Y^{*}}
$$


indicates that the derivatives are calculated at the point having coordinates $\mathrm{Y}^{*}{ }_{\mathrm{i}}$

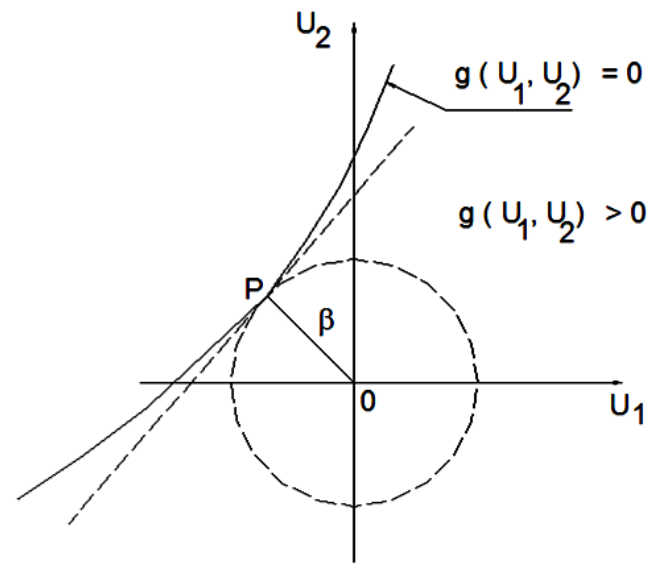

Figure 1: Minimum distance, $\beta$

$\mathbf{N}$

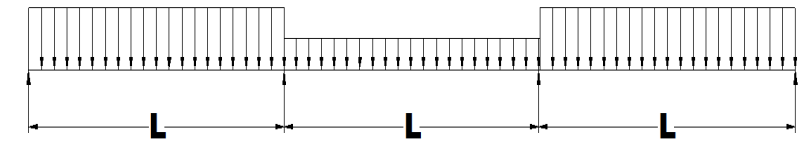

$\mathbf{N}$

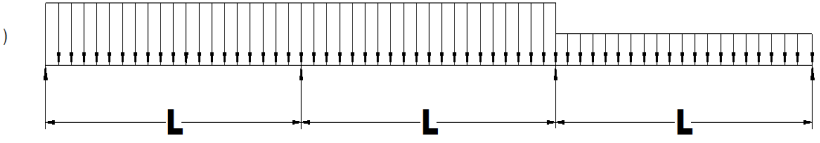

Figure 2: The Loads as $N_{1}$ and $N_{2}$ respectively $[15,16]$.

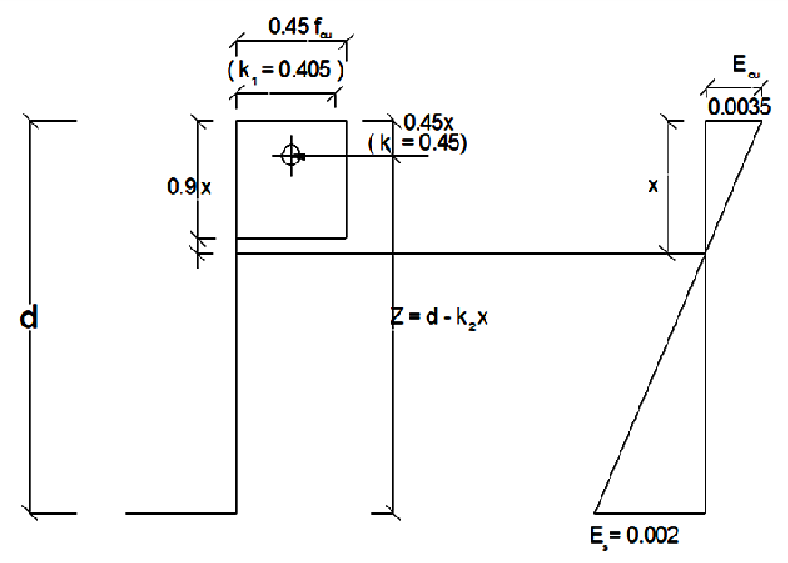

(a) Rectangular stress

(b) strain distribution

Figure 3: Simplified design stress block for ultimate limit state $[15,16]$.

By the rules of derivative of the inverse function, Equation (3) becomes:

$U_{i}=\Phi^{-1}\left[F\left(Y_{i}^{*}\right)\right]+\frac{f\left(Y_{i}^{*}\right)\left(Y_{i}-Y_{i}^{*}\right)}{\varphi\left(\Phi^{-1}\left[F\left(\begin{array}{l}* \\ i\end{array}\right)\right)\right.}$ in which $\mathrm{F}(\mathrm{)})$ and $\varphi($ ) denote the probability densities corresponding to the cumulative distributions $\mathrm{F}($ ) and $\Phi($ ) respectively. Rearrangement of Equation (5) yields:

$$
U_{Y_{i}}=\frac{Y_{i}-\left[Y_{i}^{*}-\frac{\Phi^{-1}\left[F\left(Y_{i}^{*}\right) \varphi\left(\Phi^{-1}\left[F\left(Y_{i}^{*}\right)\right]\right)\right]}{f\left(Y_{i}^{*}\right)}\right]}{\frac{\varphi\left(\Phi^{-1}\left[F\left(Y_{i}^{*}\right)\right]\right)}{F\left(Y_{i}^{*}\right)}}
$$

Hence, by comparing Equations (1) and (7), it follows that,

$$
U_{Y_{i}}=Y_{i}^{*}-\frac{\Phi^{-1}\left[F\left(Y_{i}^{*}\right)\right] \varphi\left(\Phi^{-1}\left[F\left(Y_{i}^{*}\right)\right]\right)}{F\left(Y_{i}^{*}\right)}
$$

and

$$
\sigma_{i}=\frac{\varphi\left(\Phi^{-1}\left[F\left(Y_{i}^{*}\right)\right]\right)}{F\left(Y_{i}^{*}\right)}
$$

Finally, in terms of $U_{i}$ the safety domain boundary can be expressed in the form:

$$
g\left(\mu_{1}, \mu_{2}, \cdots \cdots, \mu_{n}\right)=0
$$

The parameter $\beta$, defined as the minimum distance to this surface from the origin in the reduced coordinate system (see Figure 1) can be determined iteratively, assuming the transformed limit state is capable of differentiation, by solving the following equations:

$g\left(u_{1}^{*}, u_{i}^{*}, \cdots \cdots, u_{n}^{*}\right)=g\left(\alpha, \beta, \alpha_{2} \beta, \cdots \cdots \alpha_{n} \beta\right)=0$

in which,

$$
\alpha_{j}=\frac{\left(\frac{\partial g}{\partial U_{i}}\right)_{U^{*}}}{\sqrt{\sum_{j=1}^{n}\left(\frac{\partial g}{\partial U_{j}}\right)_{U^{*}}^{2}}} ; \quad i=1,2, \cdots \cdots, n
$$

Having obtained a satisfactory value of the minimum distance, $\beta$, corresponding to convergence of the iterative process, the operational probability of failure, $\mathrm{P}_{\mathrm{f}}$, can be computed as:

$$
P_{f}=\Phi(-\beta)
$$

where, $\Phi$ is the transformation vector.

Thus far, the derivation has assumed independent random basic variables. If $Y_{i}$ are correlated, they must be transformed to non-correlated random variables using the method proposed by some researchers [10]. Whatever the case, in the normalized space, if the original uncertainty vector has a distribution function that deviates significantly from the normal, the originally sufficiently smooth failure surfaces can become distinctively curved [9]. There is also associated with this approach the possibility of non- 
convergence of the iteration process, either because of the existence of some numerical noise in the performance function or jumps in the distribution functions [11]. For practical applications, an algorithm for solving these equations has been developed and coded by researchers [11]. Conceptually, the so-called FORM5 is based on the work in earlier studies $[7,8,12]$. A number of illustrative examples for simple cases can be found in the work of veterans like Ang and Tang [13] and Smith [14].

\section{PERFORMANCE FUNCTIONS FOR RELIABILITY ANALYSIS}

\subsection{Bending Criterion}

Two load effects may be considered in this criterion, namely; that due to simple and continuous supports. The load effect in bending for simply supported condition and for maximum applied moment $M_{a}$ is given as $[18,19]$;

$M_{a}=\frac{N_{1} L^{2}}{8}$

The load effects in a reinforced concrete continuous slab are used in this presentation. Generally, the practical approach to the analysis of continuous slabs is the application of moment distribution method. Thus, the load effect in bending for maximum applied span moment, $\mathrm{M}_{\mathrm{a} 1}$, is calculated using the moment distribution method as $[18,19]$;

$M_{a 1}=\left(77 N_{1}-19 N_{2}\right) \frac{L^{2}}{768}$

Also, the maximum applied moment at the support, $\mathrm{M}_{\mathrm{a} 2}$, is given as,

$M_{a 2}=\left(22 N_{1}-3 N_{2}\right) \frac{L^{2}}{192}$

It is required at the ultimate limit-state that the slab section should be in equilibrium. Hence, it is necessary that the tensile force, $F_{s t}$, in the reinforcement, must be balanced by the compressive force, $\mathrm{F}_{\mathrm{cc}}$, in the concrete; see Figure 2. The moment of resistance, $\mathrm{M}_{\mathrm{R}}$, for the section may be determined as,

$M_{R}=F_{c c} \cdot z=0.45 f_{c u} b x z$

Therefore, the expression for the performance function, $\mathrm{G}(\mathrm{X})$, in this limit state of bending would be,

$G(X)=M_{R}-M_{a i} ; \quad i=1,2$.

\subsection{Shear criterion}

From the results of structural analysis on the slab element, the magnitude of the critical shear force, $\mathrm{V}$, can be obtained. The ultimate shearing stress, $v$, at a section of uniform depth, d, can be determined from,

$v=\frac{V}{b d}$

In Equation (20), $b$ is the breadth of the section. The shearing force, $\mathrm{V}$, by moment distribution for a continuous slab of equal span is given as $[18,19]$;

$V=\left(0.55 N_{1}+0.049 N_{2}\right) L$

But concrete offers some amount of resistance to shearing stresses given as $v_{c}$. Thus, the resultant of the shearing stresses created by $\mathrm{V}$ is given as $\mathrm{v}-\mathrm{v}_{\mathrm{c}}$. Therefore, in designing slabs the resistance of the slab in shear in comparison to the applied shearing stress can be estimated as:

$\frac{A_{s v}}{S_{v}}=\frac{v-v_{c}}{0.87 f_{y v}}$

This can also be given as:

$\frac{0.87 A_{s v} f_{y v}}{S_{v} b}=\frac{V}{b d}[1-\eta]$

where, $A_{s v}$ is the area of shear reinforcement, $S_{v}$ is the spacing of shear reinforcement, $\mathrm{f}_{\mathrm{yv}}$ is the characteristic strength of shear reinforcement and $\eta=v_{c} / v$. The performance function for slabs in shear is therefore given as:

$G(X)=\frac{0.87 f_{y} A_{s v}}{S_{v} b}-\frac{V}{b d}[1-\eta]$

\subsection{Deflection criterion}

For simplicity, the codes $[15,16,17]$ require that the maximum vertical deflection may generally be assumed to be satisfied provided that the actual span to effective depth ratios are not greater than the limiting span effective depth ratio. This is given as:

Limiting $\frac{L}{d}=26 . m f$

where 26 = basic span effective depth ratio for continuous slabs and $\mathrm{mf}=$ modification factor. The modification factor for tension reinforcement may be expressed as follows $[18,19]$ :

$$
m f=0.55+\frac{477-f_{s}}{120\left(0.9+\frac{M_{a i}}{b d^{2}}\right)}
$$

where

$f_{s}=0.625 f_{y} \frac{A_{\text {s req }}}{A_{\text {s pro }}} \frac{1}{\beta_{r}}$

in which $\beta_{\mathrm{r}}=$ redistribution factor, $\mathrm{f}_{\mathrm{s}}=$ service stress, $\mathrm{f}_{\mathrm{y}}=$ steel yield stress, $\mathrm{A}_{\mathrm{s} \text { req }}=$ area of steel required and $A_{s \text { prov }}=$ area of steel provided.

Vol. 33, No. 3, July 2014 
Therefore, the performance function for deflection is,

$G(X)=$ Limiting $\frac{L}{d}-$ Actual $\frac{L}{d}$

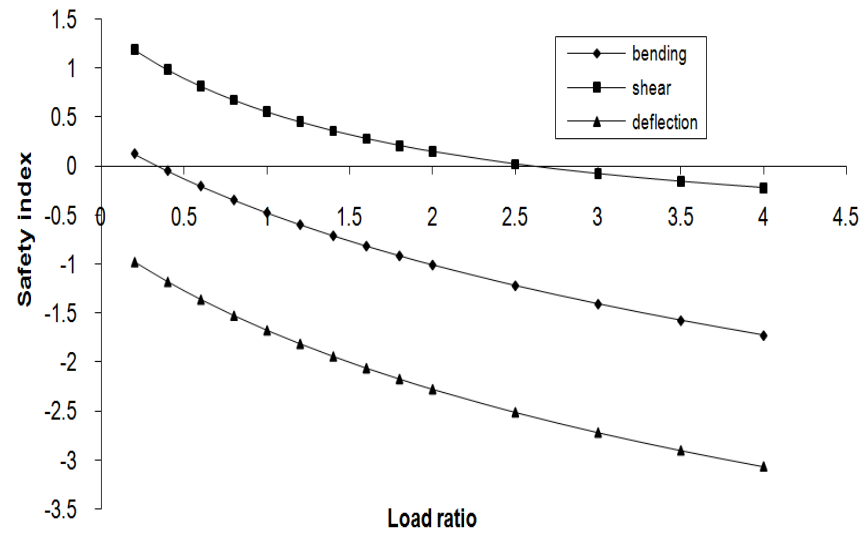

Figure 4: Implied safety levels with varying load ratios $(h=100 \mathrm{~mm})$

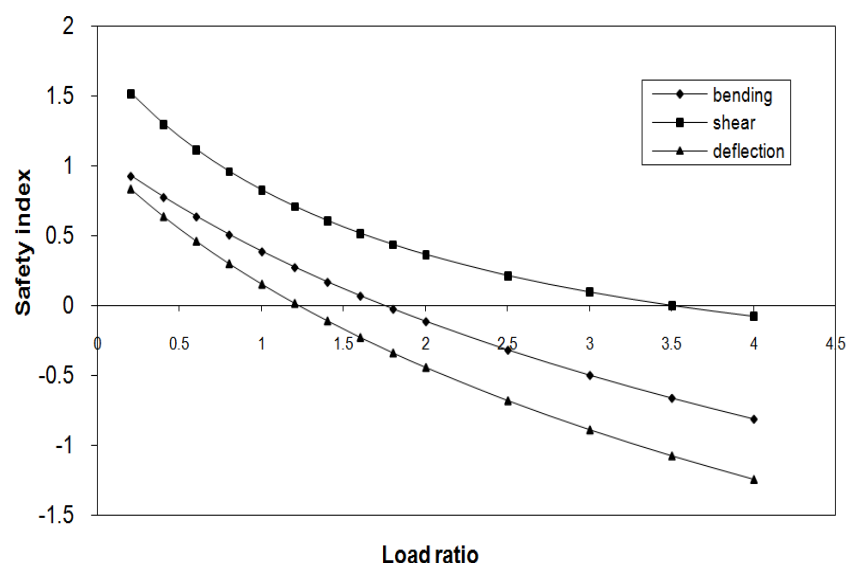

Figure 5: Implied safety levels with varying load ratios $(h=125 \mathrm{~mm})$

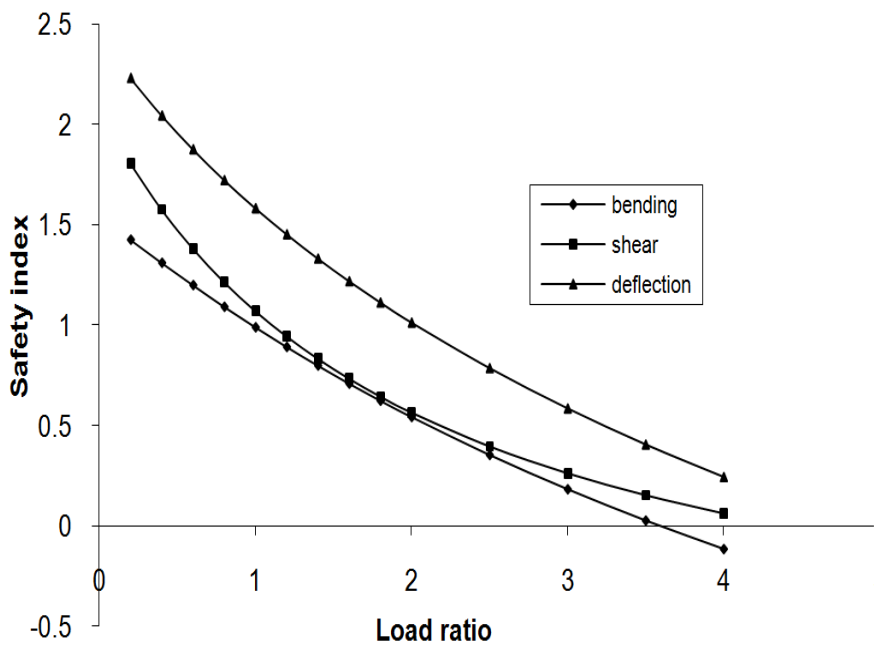

Figure 6: Implied safety levels with varying load ratios $(h=150 \mathrm{~mm})$

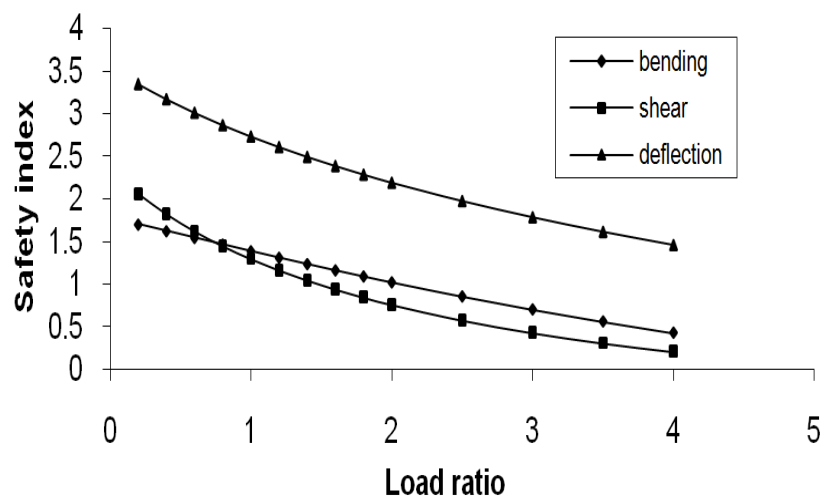

Figure 7: Implied safety levels with varying load ratios $(h=175 \mathrm{~mm})$

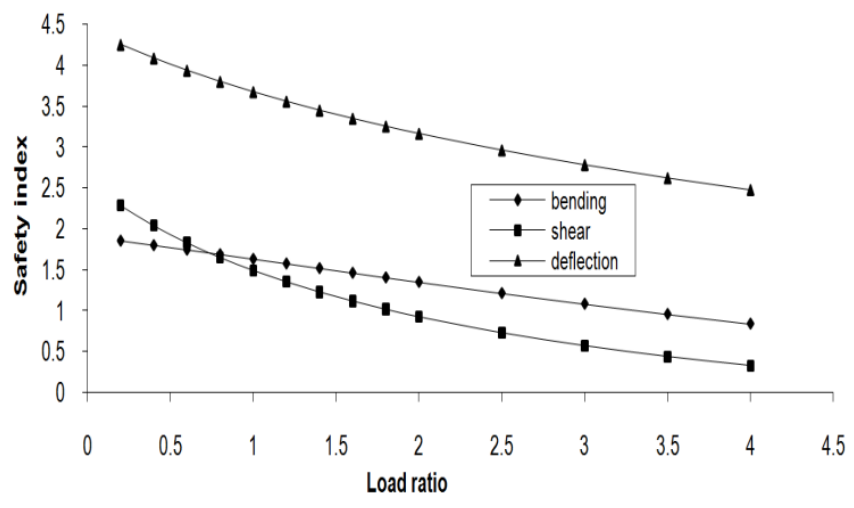

Figure 8: Implied safety levels with varying load ratios $(h=200 \mathrm{~mm})$

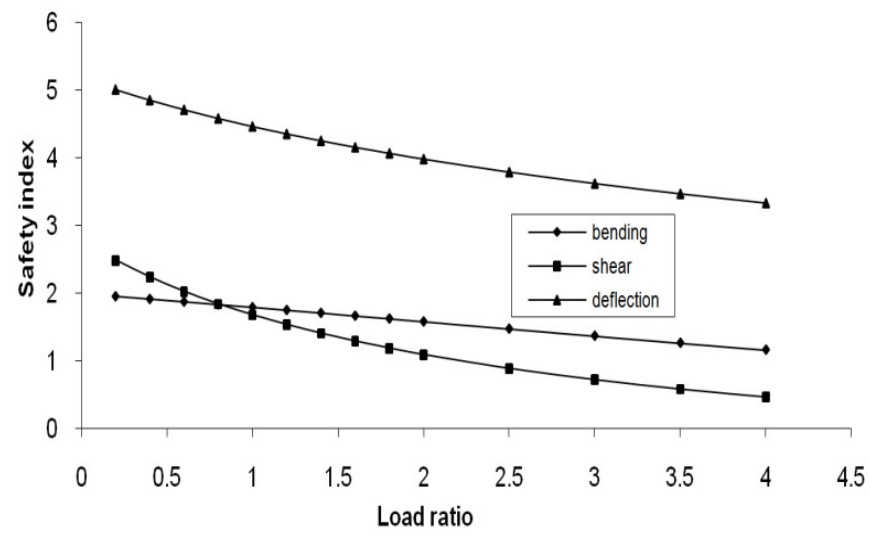

Figure 9: Implied safety levels with varying load ratios $(h=225 \mathrm{~mm})$

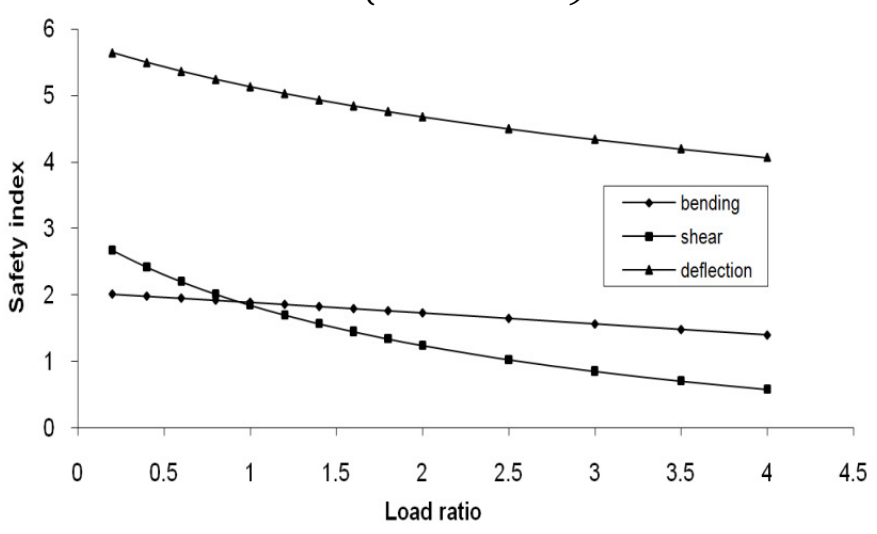

Figure 10: Implied safety levels with varying load ratios $(h=250 \mathrm{~mm})$ 


\section{DISCUSSION OF RESULTS}

Practical ranges for singly reinforced concrete solid slabs have been analyzed; that is, from $100 \mathrm{~mm}$ to $250 \mathrm{~mm}$ thickness, while considering structural spans from $3000 \mathrm{~mm}$ to $6000 \mathrm{~mm}$ in a continuous system. Typical results obtained are shown in figures 4 to 10 for continuous slabs of $4000 \mathrm{~mm}$ equal spans. These results, shown in Figures 4 to 10, vividly indicate the intrinsic reliability and corresponding probability of failure of the slabs designed according to the codes $[15,16,17]$.

It is noticed from Figures 4 to 10 that the reliability or safety levels of the slab is not uniform, for any of the criteria investigated and for the depths and spans of slab selected. Moreover, the safety levels in bending are lower than predicted in the design codes. A brief interpretation of the figures is given below.

Generally, the safety of the slabs is jeopardized with increasing load ratios in all the criteria and thickness of slab investigated. The criterion for safety is violated in all the criteria for $100 \mathrm{~mm}$ and $125 \mathrm{~mm}$ thick slabs as indicated (Figures 4 and 5) by the safety index, which is less than 2.0 as has earlier been predicted [20]. The intrinsic safety index even has a negative value, thus, suggesting that there is no safety at all. Of course, the continuous slabs with $100 \mathrm{~mm}$ and $125 \mathrm{~mm}$ thickness and $4000 \mathrm{~mm}$ spans will collapse.

In Figure 6, except for the deflection criterion, which is satisfied at load ratios less than or equal to about 0.4 , the bending and shear criteria are not satisfied. Also, Figure 7 shows that deflection criterion is adequate up to a load ratio of about 2.5; whereas, shear is only adequate for load ratios of up to 0.40 . However, the bending criterion is not satisfied at all, since the safety index is less than 2.0 in all the load ratios considered (that is, from 0.2 to 4.0 ).

In Figures 8, 9 and 10, the criterion for deflection is satisfied in all the load ratios. Moreover, the intrinsic safety level is only satisfied in shear up to a load ratio of 1.5 for the $200 \mathrm{~mm}$ thick slab, 0.8 for the $225 \mathrm{~mm}$ thick slab and up to about 1.0 for the $250 \mathrm{~mm}$ thick slab. But the bending criterion is not satisfied for the $200 \mathrm{~mm}$ thick slab, while it is barely satisfied for the $225 \mathrm{~mm}$ thick slab at a load ratio of up to 0.8 . This is the same situation with the $250 \mathrm{~mm}$ thick slab at a load ratio of up to about 1.6.

\section{CONCLUSION}

The intrinsic reliability levels of singly reinforced concrete slabs have been found to be non-uniform over the practical ranges of suspended slabs, according to the current design codes formulations. Also, the probability of failure, $\mathrm{P}_{\mathrm{f}}$, that can be achieved in the codes formulations in bending, is only 0.022 , instead of $\mathrm{P}_{\mathrm{f}}=1 \times 10^{-6}[15,16,17]$. Thus, $\mathrm{P}_{\mathrm{f}}=0.022$ corresponds to a safety level, $\beta^{\mathrm{I}},=2.015$. The value of this safety level is much lower than 3 , which, is normally recommended [20], for such structural elements. But the target safety index has been suggested [21] for upgrade by the Joint Committee on Structural Safety. However, the implied reliability levels, $\beta^{\text {I }}$, for shear and deflection are 2.670 and 5.645 respectively, while their corresponding probabilities of failures are also given as 0.00379 and $8.26 \times 10^{-8}$ respectively. The suggestion for upgrade of the safety index value to 3.8 implies that the design formulations need further review in order to meet the target for approved structural safety.

\section{REFERENCES}

1. Ditlevsen, O and Madsen, H. O. (2005) Structural Reliability Methods. John Wiley and Sons Limited, England, 2005, pp 111 - 147.

2. Ang, A. H. S, and Cornell, C. A. Reliability Bases of Structural Safety and Design. Journal of Structural Division, ASCE, Vol. 100, ST 9, Proceeding Paper 10777. September, 1974, pp. 1755 - 1769.

3. Ayyub, B. M and Halder, A. Practical Structural Reliability Techniques. Journal of Structural Engineering, ASCE, Vol. 110, No. 8, August, 1984, pp 1707 - 1724.

4. Galambos, T.V and Ravindra, M.K. Properties of steel for use in LRFD. Journal of Structural Division, ASCE, Vol. 104, No. ST9, 1978, pp 1459 - 1468.

5. Melchers, R. E. Structural Reliability Analysis and Prediction. Ellis Horwood Limited, Chichester, 1987.

6. Fiorato, A. C. Geometric Imperfections in Concrete Structures, National Building Research Report. D5, Stockholm, Sweden, 1973.

7. Rackwitz, R. Practical Probability Approach to Design, Bulletin 112. Comite European du Beton, Paris, France, 1976, pp 13 - 71.

8. Rackwitz, R and Fiessler, B. Structural Reliability Under Combined Random Load Sequences. Computers and Structures, Vol. 9, 1978, pp 489 494.

9. Fiessler, B; Neumann, H. J and Rackwitz, R. (1979) Quadratic Limit States in Structural Reliability. Journal of Engineering Mechanics Division, ASCE, Vol. 105, No.EM4, 1979, pp 661 - 676.

10. Hohenbichler, $M$ and Rackwitz, R. (1988) Improvement of Second Order Reliability Estimates by Importance Sampling. Journal of Engineering 
Mechanics Division, ASCE, VOL, 4, No. 12, December, 1988, pp 2195 - 2199.

11. Gollwitzer, S; Abdo, T and Rackwitz, R. First Order Reliability Method (FORM) Manual. RCP, Munich, Germany, 1988.

12. Hasofer, A. M and Lind, N. (1974) An Exact and Invariant First Order Reliability Format. Journal of Engineering Mechanics, ASCE, Vol. 100, No. EM1, 1974, pp 111 - 121.

13. Ang, A. H-S and Tang, W. H. Probability Concepts in Engineering Planning and Design, Vol. II: Decision, Risk and Reliability. John Wiley and Sons, Inc., New York, 1984.

14. Smith, G. N. Probability and Statistics in Civil Engineering. Nichols Publishing Company, New York, 1986.

15. British Standards Institution. BS8110: The Structural Use of Concrete: Parts 1, 2 and 3. Her Majesty's Stationery Office, London, 1985.
16. British Standards Institution. BS8110: The Structural Use of Concrete: Parts 1, 2 and 3. Her Majesty's Stationery Office, London, 1997.

17. EC2. Eurocode 2: Design of Concrete Structures. BS EN 1992-1- 2, European Committee for Standardization, CEN Brussels, 2008.

18. Reynolds, C.E and Steedman, J.C. Reinforced Concrete Designers' Handbook. 10 ${ }^{\text {th }}$ Edition. E \&F.N Spon, London, 1997.

19. Reynolds, C. E and Steedman, J. C and Threlfall, A. J. Reinforced Concrete Designers Handbook. 11 $1^{\text {th }}$ Edition. Taylor and Francis, New York, 2007.

20. Ellingwood, B. Reliability Bases of Load and Resistance Factor for Reinforced Concrete Design. National Bureau of Standards, Building Science Series 110, Washington, D. C, 1978.

21. JCSS. Recommendations for Structural Safety. Joint Committee on Structural Safety, Lexenburg, 2005. 